Lisbona, Luis.

\title{
Espacio e identidad. Identidad en relación a la cultura de redes.
}

TIPO DE TRABAJO:

Comunicación

PALABRAS CLAVE

Espacio, lugar, identidad, Internet, Net Art .

KEY WORDS

Space, place, identity, Internet, Net Art.

RESUMEN

Cuando abordamos el tema de la relación entre espacio e identidad deberíamos hablar sobre la diferencia entre espacio y lugar, mientras el espacio puede definirse como una porción de tierra no transformada por la acción humana, un residuo vacío, en cambio el lugar ha pasado a ser algo que va más allá de la materialidad que el termino sugiere debido a la implicación de experiencias emocionales e interactivas. Podríamos definir a los lugares como contenedores de identidad mediante el diálogo con la alteridad, uniéndonos a lo histórico que logra adquirir un carácter espacial. La existencia de estos lugares de contenido simbólico se han puesto en entredicho debido a la aparición de una ciudad virtual que es un decorado que propicia el trabajo, la circulación y el consumo. En base al resultado de mi investigación sobre diferentes espacios de la esfera pública he podido constatar las diferentes transformaciones que se han efectuado dentro de la misma, al reflexionar como el espacio público moderno tal y como lo conocíamos se esta transformando en un instrumento mercantilista y de consumo, adoptando las lógicas del modelo hegemónico. Es en este punto cabe preguntarse ¿de que manera estos cambios dentro del espacio público han modificado la manera en la cual creamos vínculos y por lo tanto nuestra identidad?. Es innegable que Internet ha cambiado la cara de las relaciones interpersonales. Se podría decir que Facebook ha mutado el significado de la palabra amigo, y de hecho cambiado el uso coloquial de la palabra. Los sistemas diseñados para aumentar la conectividad acarrean efectos secundarios, y en general, las aplicaciones sociales están cambiando nuestra comprensión de la amistad, las relaciones y la intimidad. Cabria preguntarse ¿cual es el papel del arte dentro de toda esta vorágine de control e inmediatez y su respuesta en el ámbito identitario?

\section{ABSTRACT}

When we address the issue of the relationship between space and identity we should talk about the difference between space and place, while space can be defined as a piece of land untransformed by human action, a vacuum residue, however the place has become something that goes beyond the material suggests that the term due to the involvement of emotional and interactive experiences. We could define places like containers of identity through dialogue with otherness, joining the historical that succeeds in acquiring a space character. The existence of these symbolic places have been questioned due to the emergence of a virtual city that is a setting that encourages work, circulation and consumption. Based on the results of my research on different areas of the public sphere I have seen the different changes that have taken place within it, reflecting as the modern public space as we knew it is becoming a mercantilist tool and consumption, adopting the logic of the hegemonic model. At this point one wonders what way these changes in the public space have changed the way in which we create links and therefore our identity ?. It is undeniable that the Internet has changed the face of interpersonal relationships. You could say that Facebook has mutated the meaning of the word friend, and actually changed the colloquial use of the word. Systems designed to increase connectivity have side effects, and overall social applications are changing our understanding of friendship, relationships and intimacy. One might ask what is the role of art in this frenzy control and immediacy and identity response in the area? 


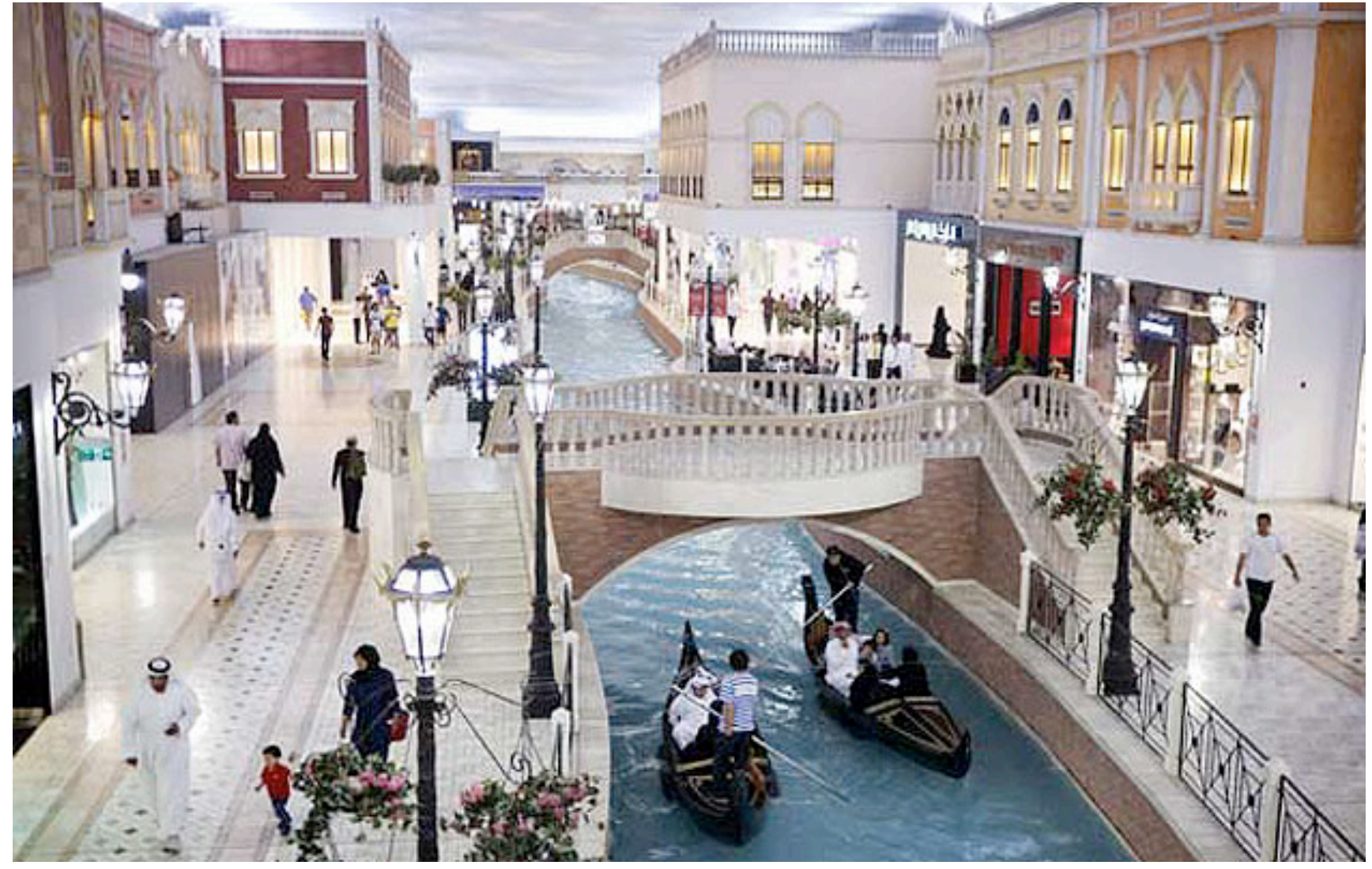

Amos Chaple, Rex Features, 2012.

A la hora de abordar el tema de la relación entre espacio e identidad deberíamos hablar primero sobre la diferencia entre espacio y lugar, mientras el espacio puede definirse como una porción de tierra no transformada por la acción humana, una especie de residuo vacío, en cambio el lugar ha pasado a ser algo que va más allá de la propia materialidad que el termino sugiere debido a la implicación de experiencias emocionales e interactivas a través del tiempo. Es por ello que podemos afirmar que esta transformación acaecida a pequeña escala dentro de un espacio, está relacionada con el habitar y la simbolización generada por el drama de lo humano, o nuestro ser en el mundo, ese Dasein como diría Martin Heidegger. Por lo tanto podríamos definir a los lugares como contenedores de identidad mediante, como nos cuenta Marc Augé, el diálogo con la alteridad, uniéndonos a lo histórico que logra adquirir un carácter espacial. La existencia de estos lugares de contenido simbólico que sugieren un sentido del lugar y proponen dimensiones visibles pero más evocadoras, se han puesto en entredicho debido a la aparición de una ciudad virtual que simplemente es un decorado que propicia el trabajo, la circulación y el consumo. Es una ciudad neutra y sin historia previa, que nos transporta a una concepción atemporal y deslocalizada del espacio urbano, donde la globalidad y universalidad son los valores preponderantes, negando y colonizando todas aquellas manifestaciones espaciales disonantes y generando una manera de representación de ciertos valores ideológicos que tienen como consecuencia modos de relación y comportamiento propiciados por el propio funcionamiento y ordenamiento espacial de la ciudad. Es por ello que la conquista del espacio tanto real como virtual se presenta como una de las cuestiones mas importantes dentro de nuestra experiencia espacial, generando lugares de donde proyectar diferentes formas de vida y de relación en algunos casos de manera efímera, intangible o invisible. Por lo tanto el espacio público moderno tal y como lo conocíamos se esta transformando en un instrumento mercantilista y de consumo, adoptando las lógicas del modelo hegemónico. Esta homogeneización también alcanza los valores culturales, los cuales presentan un intento de uniformar todos aquellos discursos discrepantes.

Rem Koolhaas en su obra Espacio Basura, "Conceptualmente, cada monitor, cada pantalla de televisión es el sustituto de una ventana; la vida real está dentro, el ciber-espacio se ha convertido en la naturaleza exterior". Con esta frase Koolhaas reflexiona sobre los cambios antes citados que tienen un alcance mucho más profundo de lo que en un primer momento podríamos esperar y llega a aspectos como la percepción de nuestro propio hábitat como individuos, y la mezcla del espacio privado en parte del publico debido al crecimiento de la esfera mediática y por lo tanto de contenidos personales dentro de esta. Es innegable que Internet ha cambiado la cara de las relaciones interpersonales, e incluso ha creado nuevas tipologías. Se podría decir que Facebook ha mutado el significado de la palabra amigo, y de hecho cambiado el uso coloquial de la palabra. Los sistemas diseñados para aumentar la conectividad acarrean efectos secundarios no esperados, y en general, las aplicaciones sociales están cambiando nuestra comprensión de la amistad, las 
relaciones y la intimidad. Cuando un usuario piensa sobre el concepto de Internet, pensamos en un ecosistema social o un ágora, pero este modo de pensamiento tiene su origen en las utopías desarrolladas en los comienzos de Internet, las cuales ya no tienen vigencia hoy día debido a la implementación de la web 2.0, la cual supone el funcionamiento de métodos de identificación, vehiculización de nuestro comportamiento y visualización de nuestro entorno a través de nuevas herramientas virtuales que derriban estas utopías de Internet como espacio público, anónimo y de libre circulación de información. Ya Paul Virilio en su obra de 1999 El Cibermundo, la política de lo peor, se cuestiona sobre cuales son las implicaciones futuras del progreso tecnológico, la creación de un tiempo global y único, gracias a la instantaneidad de las comunicaciones y el transito de información, y lo más importante, quien controla esta información y como se aplica en áreas como el consumismo y el control. Cabria preguntarse ¿cual es el papel del arte dentro de toda esta vorágine de control e inmediatez? Quizás divergir y aportar una visión disidente, alternativa o heterodoxa sobre todos estas cuestiones identitarias. La esfera pública debe ser el escenario que la práctica artística debe usar para cuestionar las transformaciones vividas por la misma en el ámbito mediático e identitario.

En Internet la comunicación y la interacción estarían sujetas a las diferentes naturalezas de la identidad que mostramos, bien coincidente con el mundo físico y que viene propiciada por el funcionamiento $\mathrm{d}$ el a web 2.0, o bien identidades ficticias creadas ex profeso para determinada labor o contexto y que asume un rol de mascara bajo la que nos escondemos. La identidad online ha adquirido cualidades de producto que nos ha llevado a un selfbranding constante. La construcción y exhibición identitaria, a partir de la Web 2.0. ha dejado de plantear la multiplicidad y el anonimato como características principales para dar paso a un yo que quiere hablar de si mismo y hacerse a si mismo, mediante la autopromoción de un individuo influido por las prácticas y discursos del capitalismo sujetos a las leyes del mercado, es sobre todo, en el caso de las principales Redes Sociales y plataformas como Youtube, Vimeo, un escenario en el cual la identidad se construye con respecto a los demás usuarios, entendida como un actuar mediante el cual generamos relaciones, y que funciona como un mercado de la observación en el que cada usuario produce contenidos a la vez que consume los de otros usuarios, dando origen a términos como prosumer. Como ya el 1970 Marshall McLuhan nos anunciaba en su libro Take Today, esto se encuadra como consecuencia del avance en la tecnología, el cual ofrece herramientas mediáticas de producción al alcance del publico en general. Este modo de actividad tiene como objetivo remarcar la naturaleza participativa y relacional de esta identidad como forma de actividad que nosotros mismos desarrollamos dentro de un espacio. Este tipo de construcción identitaria espectacularizada busca la mirada del otro para constituirse como tal. Como Jacques Lacan nos decía con su concepto de la teoría psicoanalítica denominado El estadio del espejo, el bebé por primera vez toma conciencia de si mismo cuando se reconoce en el espejo como un ente autónomo y aprende a distinguirse de sus semejantes mediante esta imagen especular. Tiene implicaciones determinantes para la formación del yo como instancia psíquica según el propio Lacan. Por lo tanto podríamos denominar este nuevo medio como el espejo el cual necesitamos mirarnos para reconocernos respecto a la multitud interconectada, un espejo que nos devuelve la mirada en forma de interacción de otros usuarios sobre nuestra propia autoconstrucción identitaria en relación a la cultura de redes, que adquiere forma de marca o producto encaminado a una autopromoción personal dentro del capitalismo globalizado de la web 2.0. Es por ello que se podría definir la identidad online no como algo estático, sino como un constructo moldeable, como una acción cotidiana que realizamos sobre nosotros mismos diariamente. La configuración del yo, ya no es única o unilateral, es a través de la interacción en Internet como construimos múltiples perfiles, a la vez que difuminamos límites antes establecidos, convirtiéndose este medio en un territorio de experimentación, donde el individuo se autorepresenta.

Dentro de esta vorágine de autoconstrucción, la imagen es una de las principales herramientas a la hora de autorepresentarnos dentro de la red. Se ha constituido como el interfaz mediante el cual nos comunicamos dentro del hábitat de las redes sociales. La finalidad de establecer interacciones es crear significados compartidos, construcciones de la realidad inmediata y deseos mutuos a partir de los símbolos que se intercambian. Este entorno mediático da la oportunidad al usuario de ocupar un lugar en el mundo para dar sentido a sus actos y a su propia existencia. Son marcos de referencia, encuadres, que ordenan las experiencias y hechos de la cotidianeidad para dar significado a la realidad. De esta manera el usuario compone su yo social y subjetivo a la vez. Esto produce una identidad influenciada por el propio medio en el cual esta se desarrolla, obligándonos a seleccionar lo que se muestra y se omite sobre nosotros mismos dentro de la vida cotidiana que realizamos cada día, y que simboliza una conquista de la posibilidad de manofacturar nuestra propia imagen personal y contraponerla a la de los demás. Su aspecto más seductor se encuentra en la narración como aspecto inseparable de la identidad y que se caracteriza por lo inmediato, indiscreto y exhibicionista en ocasiones de esta hibridación entre modelos textuales y visuales de representación interactiva para con los otros usuarios que realizamos diariamente dentro de lo que se asemeja a una especie de performance extendida que actúa sobre nuestro propio yo. Laís Pontes es una artista nacida en Brasil, la cual realizo la obra Project Born Nowhere en 2011. Nos muestra un acercamiento participativo al concepto de identidad, a través de las redes sociales. Esta artista moldea a partir de su propio rostro un gran número de identidades de mujeres que no existen realmente, que son realizadas con herramientas de retoque fotográfico. Pontes subió estos retratos manofacturados a la página de Facebook creada ex profeso para este proyecto sin añadir algún dato más esperando que los usuarios completaran la personalidad de cada mujer inspirándose en el lema What one sees is what one wants to see. Después de analizar las contribuciones, Pontes da el toque final a la identidad de su creación, añadiendo la descripción que a partir de las intervenciones de los usuarios ha sido conformada en la página. Por otro lado habría que realizar una reflexión sobre la noción del avatar y su impacto en la constitución de la identidad en Internet caracterizada por su multiplicidad y disolución dentro de un sin fin de cambios y mutaciones constantes que son un reflejo de lo voluble y cambiante de este medio, y de nuestras representaciones corpóreas dentro del mismo, como contrapunto a lo experimentado en la redes sociales, y que se contrapone a las lógicas identificatorias de la web 2.0. 
El avatar aparece como un medio mediante el cual identificarse en un espacio virtual o metaverso, posibilitando el hecho de estar en varios lugares al mismo tiempo, siendo por lo tanto una especie de prótesis virtual que extiende nuestras acciones y nos representa como individuos, teniendo siempre como meta mostrar lo que queremos ser, pero con la posibilidad de customizar y configurar nuestra propia exterioridad y apariencia de la manera que estimemos oportuna, abriendo un gran abanico de opciones y diferentes maneras de autorepresentación dentro de estos espacios. Es una vía de escape a las fijaciones identitarias que dependen de la corporalidad física, y que dan la posibilidad de usar el propio yo mediante su representación corporal como una metáfora que pone en tela de juicio este cambio de rumbo hacia lo real y cotidiano, pero que poco a poco va disolviéndose en un océano de imágenes cotidianas de millones de usuarios que se contraponen a la virtualidad de los metaversos en los cuales los avatares se desenvuelven. La serie de imágenes 13 Most beautiful Avatars realizada en 2007 por Eva y Franco Mattes, muestran una serie de impresiones de rostros de avatares de Second Life, que al ser simplemente avatares componen autorretratos imaginarios de esos usuarios. Esta serie está inspirada en la serie 13 Most Beautiful Boys and Girls realizada por Andy Warhol. En esta serie Eva y Franco querían poner de manifiesto la inversión creativa que supone la realización del alter ego virtual de cada individuo, apareciendo la noción de retrato clásico que sirve para mostrarnos como nuestros propios proyectos de lo que en realidad queremos ser, siendo en realidad el propio objetivo del retrato en si. Gracias a Internet hemos disuelto las barreras antes férreas de los público y lo privado a la vez que hemos cambiado nuestra dimensión sobre el tiempo comprimiéndola y generando nuevas experiencias en el ámbito de lo virtual generando performidad más allá de una simple puesta en escena y produciendo experiencias en lugar de una recreación que podemos compartir más allá de los tradicionales conceptos de territorio y espacio. Eva y Franco Mattes realizaron la seria Synthetic Performances desde 2007 a 2010 en la cual realizaban un gran número de reconstruccion de acciones de carácter más transgresor dentro del mundo de la corporalidad y que son realizadas dentro del metaverso Second Life, incluyendo reconstrucciones de obras de Marina Abramovic , Gilbert \& George , Vito Acconci , Chris Burden y Valie Export, y en las que cualquiera podía participar conectándose a este metaverso.

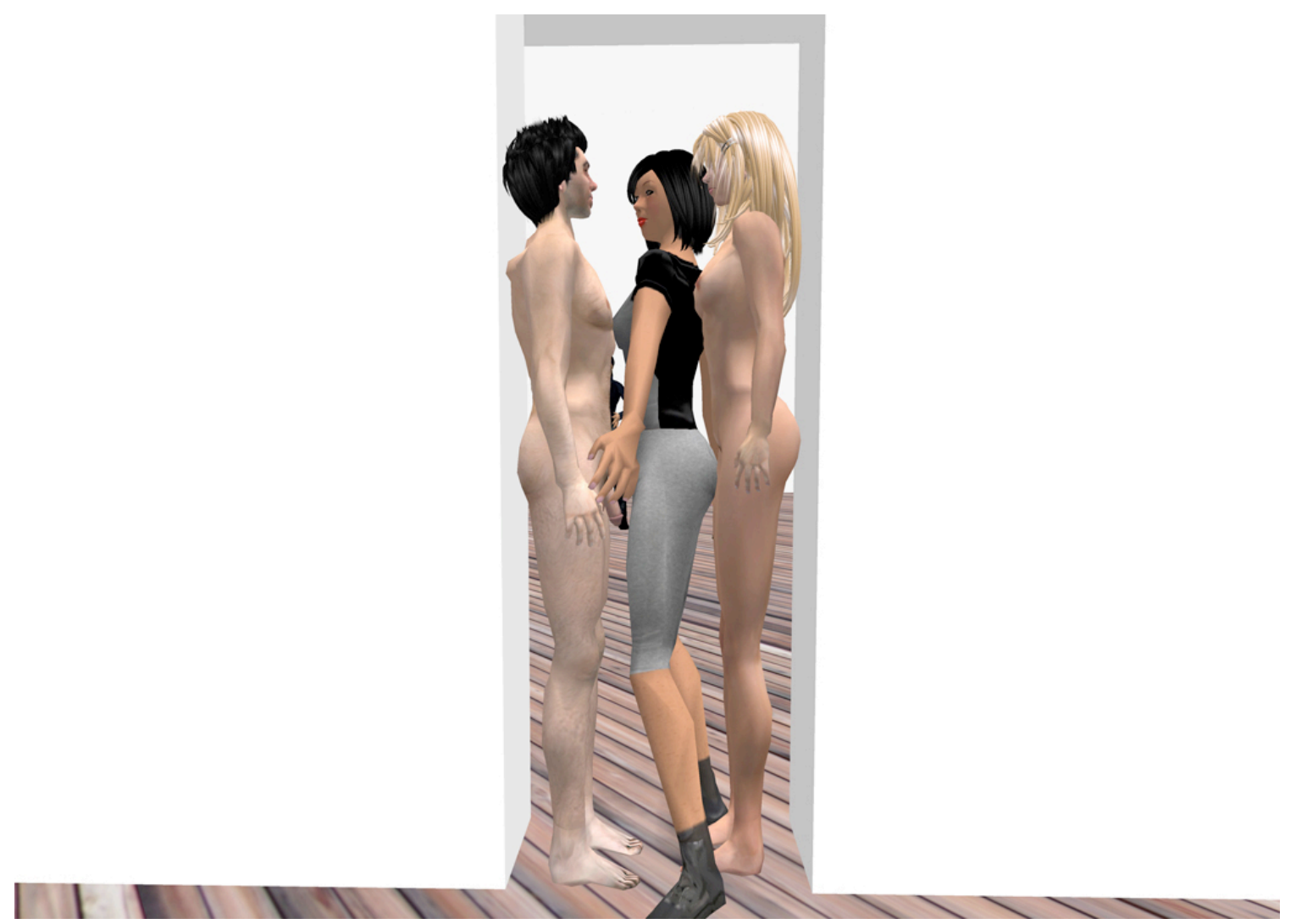

Eva y Franco Mattes, Synthetic Performances, 2007-2010.

Como nos narra Juan Martín Prada en su libro Practicas Artísticas en Internet en la Época de las Redes Sociales, el tema de la identidad en Internet tuvo en los años 90 la tarea de desentrañar el tipo de participación que llevamos a cabo dentro de este espacio, conceptualizando Internet como un actuar vinculado con el área de lo relacional, lo cual fue del todo acertado si lo que queremos es redefinir el concepto de identidad, ya que esta se conforma con respecto a los demás, recordemos la máxima de Marc Augé "no hay identidad sin alteridad". Es por lo tanto clarificador el hecho de que la denominada web 2.0 necesite de la actividad de los usuarios para funcionar, generando cuerpos de datos mediante los cuales poetizar sobre lo múltiple y lo colectivo. Claros ejemplos de esta tendencia es la obra de artistas como Laura Bey o Roberto Aguirrezabala, donde la autoexperimentación poética de nosotros mismos sucede en el propio medio, siendo parte del sistema explorado, mostrando los propios obstáculos para el dialogo y el entendimiento 
generados por la perdida de la privacidad, monitorización e imposición de reglas que aluden al papel de la identidad en la cultura de redes.

Po otro lado desde la segunda década del presente siglo las dinámicas empresariales han sido orientadas a potenciar los factores emancipadores e igualitarios de la conectividad, generando una ideología del consumo que busca la gestión de la identidad y la autorepresentación. Este modo de convergencia entre dominación y libertad tiene por objetivo la capacidad de regular la subjetividad, cobrando especial relevancia el tema de la reafirmación del yo dentro de la práctica artística, usando como herramienta para ello las redes sociales y el fenómeno blog. Este es un yo identitario, que quiere hablar de si mismo, generando un compromiso con la expresión desde un punto de vista personal, propio de las redes sociales actuales donde aportamos nuestra información real, produciendo comunidades que tienen como objetivo mostrar nuestro lado más particular e íntimo, produciendo una autoconstrucción frente a los demás. Este, según sus propios creadores es el factor primordial que ha llevado al éxito a este tipo de redes, el uso de la identidad real, frente al uso mayoritario de identidades ficticias durante la web 1.0.

La generación de falsas identidades y juegos antiidentitarios van a conformar las principales estrategias a ala hora de intentar evadir los intentos de las grandes redes sociales de gestionar lo que se muestra como realidad o verdad respecto a nosotros mismos. Paradigmático de este tipo de planteamientos es la obra Peoples de 2007 donde los artistas Gregory Chatonsky y Jean Pierre Balpe construyen, mediante un generador de texto, biografías imaginarias que son acompañadas por imágenes de Flickr.

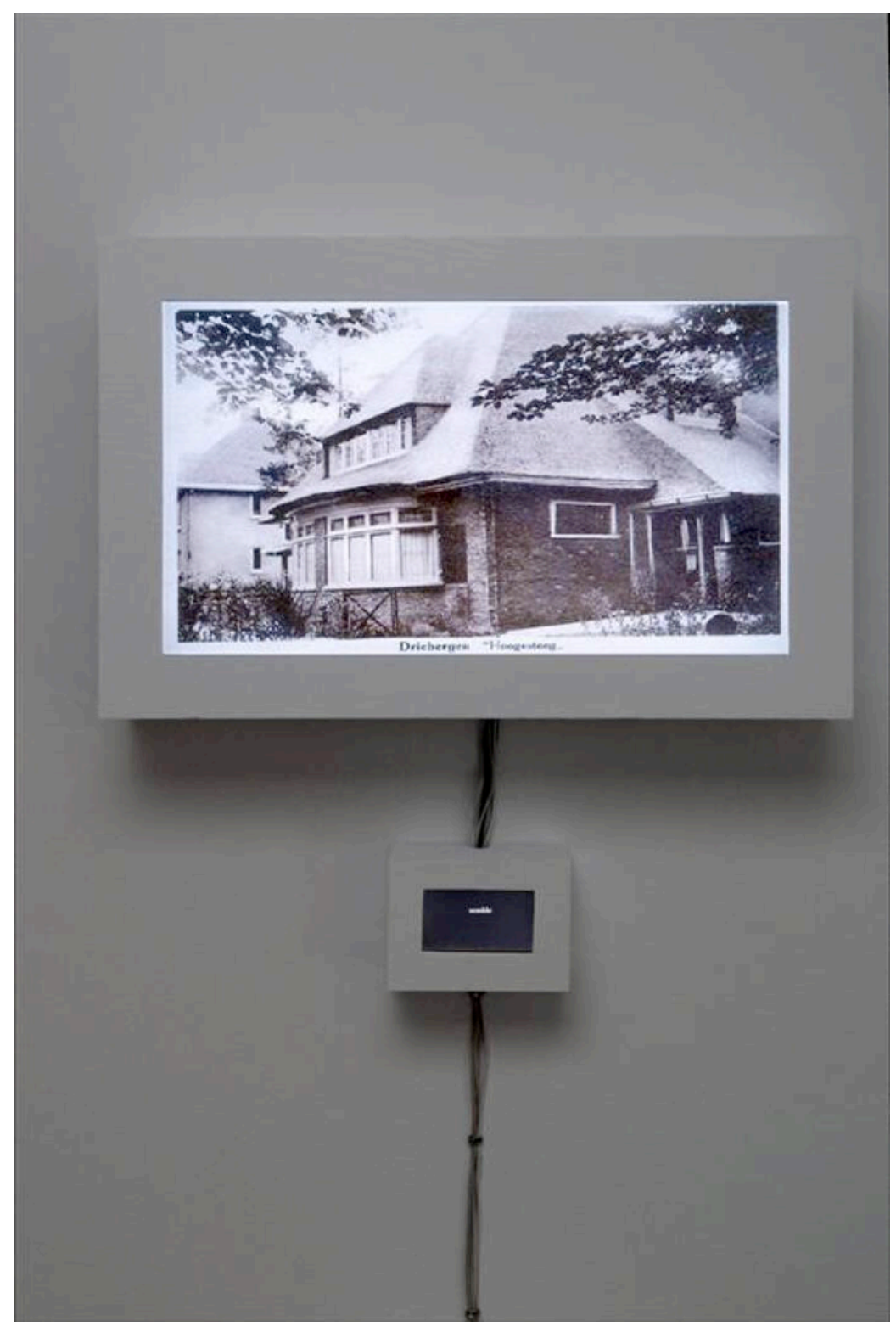

\section{Gregory Chachonsky, Peoples 2007}


Otra de la grandes problemáticas cercanas a la identidad nos recuerda el propio hecho de la desigualdad sexual o racial escondida detrás de muchas tecnologías de la conectividad real. Internet sigue perpetuando los mismos estereotipos de la identidad de género debido a haber sido estructurado de acuerdo al sistema económico imperante heredero del patriarcado. La aparición del ciberfeminismo en los 90 propone una disolución de la fronteras entre géneros. Pasan de proponer un lenguaje femenino en la red a proponer estrategias de dislocación y sobrexposición identitaria, como podemos constatar en la obra de Petra Cortright, Sprkelles.

Respecto a la desigualdad social podemos señalar las obras centradas en las políticas de la autorepresentación y exclusión dentro de las formas de producción del imaginario amateur, como podemos ver en la obra de Daniela Ortiz, 97 empleadas domesticas, donde aparecen accidentalmente las susodichas empleadas dentro de fotografías de la clase alta peruana difundidas por la redes sociales, haciendo referencia a lo que aparece fuera de plano en el sentido social de la expresión.

En definitiva cabria reflexionar sobre nuestro nuevo espacio identitario en base a las nuevas realidades mediáticas que han aparecido en los últimos decenios, para concluir que gran parte de nuestro nuevo espacio simbólico reside en cada monitor de manera intangible, en parte por la nueva aparición de herramientas que propician la autoconstrucción de uno mismo respecto a los demás, pero también como consecuencia de un espacio público que ha abandonado en gran parte su función de ágora en la cual se producen relaciones o intercambios, generando significado mediante el uso continuado del mismo. Dentro de la red la identidad ha adquirido de manera dramática el estatus de producto abierto al público que se construye en base a el y las interacciones que se producen dentro del espacio mediático de Internet. Las lógicas de funcionamiento de la web 2.0 han producido una hibridación de identificación y anonimato que coexisten en diferentes espacios de Internet, siendo la primera la opción hegemónica en el campo de la autorepresentación bien sea mediante el autorretrato o narraciones de tipo autobiográfico basadas en representaciones verboicónicas. Es por ello que siguiendo el ejemplo de artistas como Gregory Chatonsky y Jean Pierre Balpe debemos cuestionar la manera en la cual nos representamos y construimos frente a los demás teniendo conciencia de las implicaciones que la manera en la cual usamos los media tiene sobre la construcción cotidiana de nosotros mismos como proyecto identirario colectivo.

\section{FUENTES REFERENCIALES}

ALBELDA, JOSÉ LUÍS, SABORIT, JOSÉ, La Construcción de la Naturaleza, Valencia, Generalitat Valenciana, 1997.

AUGÉ, MARC, Los No Lugares, Madrid, Gedisa, 1993.

BARLOW, J. P., A declaration of the independence of cyberspace [en línea], 1996, [consulta 9 de Junio de 2014], disponible en $<$ homes.eff.org/ barlow/Declaration- Final.html>.

BARLOW, JOHN, A Not Terribly Brief History of the Electronic Frontier Foundation, 1996, [consulta 9 de Junio de 2014], disponible en <https://w2.eff.org/Misc/Publications/John_Perry_Barlow/HTML/not_too_brief_history.html >.

BAUDRILLARD, JEAN, La Agonía del Poder, Madrid, Círculo de Bellas Artes, 2006.

BAUMAN, ZYGMUNT, Amor Liquido: Acerca de la fragilidad de los vínculos humanos, Buenos Aires, Fondo de Cultura Económica , 2005.

BENJAMIN, WALTER, La Obra de Arte en la Época de la Reproductibilidad Técnica, México D.F., Ítaca, 2003.

BREA, JOSÉ LUIS, Cultura RAM: mutaciones de la cultura en la era de la distribución electrónica, Barcelona, Gedisa, 2007.

CASTELLS, M., La Galaxia Internet, Barcelona, Plaza y Janés, 2001.

DE CERTEAU, MICHEL, La Invención de lo Cotidiano 1 Artes de Hacer, México D.F., Universidad Iberoamericana, 2000.

DEBORD, GUY, La Sociedad del Espectáculo, Madrid, La Marca Editora, 2008.

DONATH, JUDITH S., Identidad y decepción en la comunidad virtual, en Smith, Marc A.; Kollock, Peter, Comunidades en el Ciberespacio, Londres, Routledge, 1999. 
DREYFUS, SUELETTE, Underground: Tales of Hacking, Madness and Obsession on the Electronic Frontier, Sidney, Reed Books Australia, 1997.

GIDDENS ANTHONY, Modernidad e Identidad del Yo, Barcelona, Ediciones Península, 1997.

GRUPO AUTÓNOMO A.F.R.I.K.A.; BLISSET, L.; BRÜNZELS, S., Manual de guerrilla de la comunicación, Barcelona, Editorial Virus, 2000. HIMANEN, P., The hacker ethics, New York, Random House, 2002.

KLEIN, NAOMI, No Logo, London, Flamingo, 2000.

KOOLHAAS, REM, Espacio Basura, Barcelona, Gustavo Gili, 2007.

LACAN, JACQUES, Le stade du miroir comme formeteur de la fonction du je, telle qu'elle nous est révélée dans l'expérience psychanalytique, Paris, Écrits Seuil, 1966.

MANEN, MARTí, Salir de la exposición (si es que alguna vez habíamos entrado), Barcelona, Consonni, 2012.

MARTÍN PRADA JUAN, Otro tiempo para el arte, Valencia, Sendemá, 2013.

MARTíN PRADA JUAN, Prácticas Artísticas en Internet en la Época de las Redes Sociales, Madrid, Akal, 2012.

MCLUHAN, MARSHALL, Understanding Media, Cambridge, Mit Press, 1994.

PÁGINA OFICIAL de los artistas Eva y Franco Mattes, [en línea], 2009, [consulta 18 de Marzo de 2014] disponible en <http://0100101110101101.org/>.

PORTER, DAVID, Internet Culture, New York, Routledge Inc, 1997.

POSTMES, TOM; JETTEN, JOLANDA, Individuality and the Group, Amsterdam, Sage. Publications LTD, 2006.

SAN CORNELIO GEMMA, Arte e Identidad en Internet, Barcelona, Editorial UOC,2008.

STALLMAN, R.; LESSIG, L.; GAY, J., Free software and free society, Cambridge, Free Software Foundation, 2002.

VIRILIO, PAUL, Ciudad Pánico, el afuera comienza aquí, Buenos Aires, Libros del Zorzal, 2006.

VIRILIO, PAUL, El Cibermundo, la política de lo peor, Madrid, Cátedra, 1997.

WHITNEY SAMUEL, ALEXANDRA, Hacktivism and the Future of Political Participation, Cambridge, Hardvard University, 2004. 